\title{
Unrest at the Laguna del Maule volcanic field 2005-2020: renewed acceleration of deformation
}

\author{
H. Le Mével ${ }^{1}$ (D) - L. Córdova ${ }^{2}$ - C. Cardona ${ }^{2}$ - K. L. Feigl ${ }^{3}$
}

Received: 2 November 2020 / Accepted: 6 April 2021 / Published online: 19 May 2021

(C) The Author(s) 2021

\begin{abstract}
The Laguna del Maule volcanic field in Chile has been exhibiting unrest since 2005. New GPS and InSAR data reveal a second episode of accelerated deformation beginning in late 2016 and continuing through May 2020, with an uplift rate $>290 \mathrm{~mm} /$ year between 2019 and 2020. To explain the spatial and temporal pattern of deformation, we apply a dynamic model of viscous magma flowing through a conduit into a fluid-filled reservoir surrounded by a heterogeneous, viscoelastic crust. A Monte Carlo procedure optimizes the ellipsoid reservoir geometry and the inlet pressure history. The two episodes of accelerating uplift are each modeled with a pressure increase rate of $\sim 9 \mathrm{MPa} /$ year. Since $2016,0.10 \mathrm{~km}^{3}$ of magma was injected into the system for a total of $0.37 \mathrm{~km}^{3}$ since 2005 .
\end{abstract}

Keywords Volcanology · Geodesy · Deformation · Laguna del Maule · GPS · InSAR · Volcanic unrest

\section{Introduction}

The volcanic field at Laguna del Maule (LdM) in the southern Andes exhibits recent silicic volcanism and ongoing, rapid deformation, but no historical eruption (Andersen et al. 2018; Andersen et al. 2019). It has been uplifting faster than $200 \mathrm{~mm} / \mathrm{year}$ since 2007 (Feigl et al. 2014; Le Mével et al. 2015; Le Mével et al. 2016). Episodes of unrest characterized by ground uplift are commonly observed at large silicic caldera systems (Sandri et al. 2017), as illustrated by the recent unrest at Domuyo volcano in Argentina (Astort et al. 2019; Lundgren et al. 2020), Long Valley caldera (Montgomery-Brown et al. 2015), and Yellowstone caldera (Chang et al. 2010). Episodes of uplift without subsequent eruptions have also been observed at mafic calderas such as Alcedo volcano in the Galapagos

Editorial responsibility: J. Ruch

$凶$ H. Le Mével

hlemevel@carnegiescience.edu

1 Carnegie Institution for Science, Earth and Planets Laboratory, Washington DC, USA

2 Observatorio Volcanológico de los Andes del Sur (OVDAS), SERNAGEOMIN, Temuco, Chile

3 Department of Geoscience, University of Wisconsin - Madison, Madison, WI, USA
(Galetto et al. 2019). Surface uplift signals pressurization of the underlying magma reservoir(s) which can result from emplacement of new magma and/or perturbations to pore-fluid pressure in the associated hydrothermal system (e.g., Mogi 1958; Gottsmann et al. 2006; Dzurisin 2007; Troiano et al. 2011; Coco et al. 2016). Surface uplift can also presage eruptive activity (Sigmundsson et al. 2010; Peltier et al. 2008). One of the outstanding challenges in interpreting measurements of volcanic deformation thus lies in determining when a pre-eruptive stage is reached. Since the long, multi-sensor time series of geodetic measurements at LdM includes episodes of quiescence, acceleration, and deceleration, this data set provides a unique opportunity to study magma emplacement at long-lived magmatic systems during an inter-eruptive time interval.

The LdM volcanic field sits in the Southern Volcanic Zone of Chile (Fig. 1). Previous InSAR and GPS studies have revealed three phases of ground deformation for the ongoing geodetic unrest at LdM: (1) No displacement was observed between 2003 and 2004 (Fournier et al. 2010); (2) Ground uplift accelerated from some time before 2007 through 2010 with rates exceeding $200 \mathrm{~mm} /$ year (Feigl et al. 2014; Le Mével et al. 2015), and (3) Uplift continued with slowly decelerating rates from 2010 to 2016 (Le Mével et al. 2016). The deformation affects an area of $\sim 500$ $\mathrm{km}^{2}$ centered on the western shore of the lake basin. This area includes $\sim 40 \mathrm{~km}^{3}$ of rhyolite erupted since the last glaciation (ca. $20 \mathrm{ka}$ ) and as late as ca. $2000 \mathrm{ka}$ from at least 


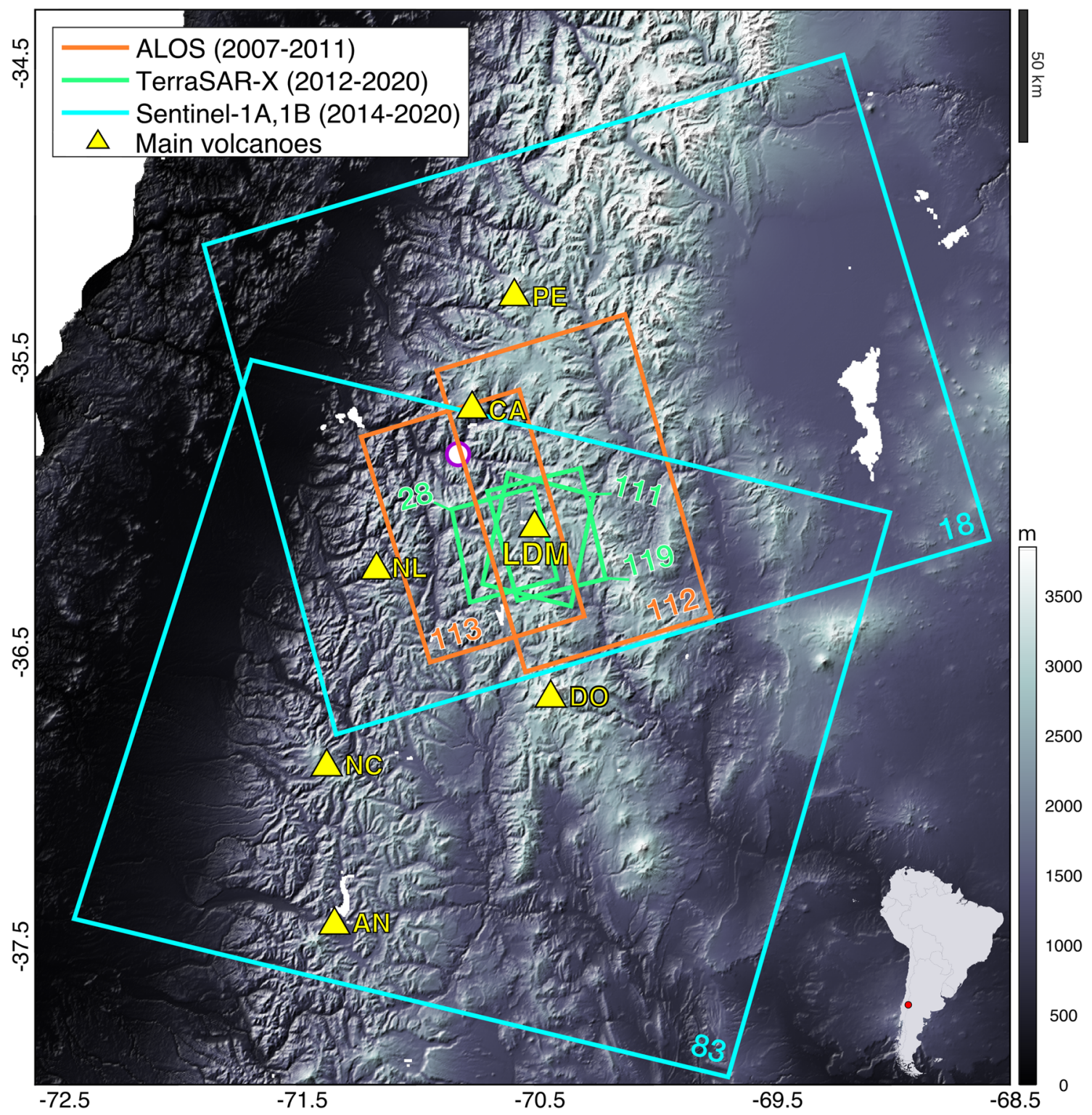

Fig. 1 Regional location map of LdM volcanic field in Chile. NASA SRTM3 DEM (grayscale), main arc volcanoes of the Southern Volcanic Zone (yellow triangles) - PE, Peteroa; CA, Cerro Azul; NL, Nevado de Longavi; DO, Domuyo; NC, Nevado de Chillan; AN,

24 vents distributed around the lake basin (Andersen et al. 2018; Andersen et al. 2019). The source of uplift has been modeled as an opening sill at a depth of $5 \mathrm{~km}$ (Feigl et al. 2014). Le Mével et al. (2016) introduce analytic solutions for a dynamic model of magma injection into a spheroid chamber to explain nonlinear evolution of uplift observed in the displacement time series.

Previous studies have imaged the magmatic system at LdM, including: a low-density body at a depth of 2 to $4 \mathrm{~km}$ sitting directly above the modeled deformation source (Miller et al. 2017), a conductor extending laterally northward and downward to a depth of $15 \mathrm{~km}$ (Cordell
Antuco - SAR frame outlines (color-coded rectangles with track number), and MAUL continuous GPS station used as a reference for the GPS time series (white circle). Lower-right inset shows location of LdM (red dot) within South America

et al. 2018), and a low seismic velocity zone of $\sim 500 \mathrm{~km}^{3}$ (Wespestad et al. 2019; Bai et al. 2020). A network of active normal faults striking NE-SW was also revealed onshore and in the lake sediments (Peterson et al. 2020; Garibaldi et al. 2020). Petrologic and geochemical findings at LdM support the physical model of volatile-rich magma injection into an existing reservoir (Klug et al. 2020; Andersen et al. 2018; Andersen et al. 2019).

In this study, we analyze geodetic data at LdM to calculate time series of displacement from 2007 to 2020 and model them in terms of magma input to the reservoir. 


\section{GPS and InSAR data}

\section{GPS}

Five continuously recording GPS stations have been installed since 2012 (Fig. 2). Precise point-positioning (Zumberge et al. 1997) using GIPSY-OASIS (release 6.4) provides daily estimates of station coordinates referred to the stable South America reference frame with uncertainty better than $1 \mathrm{~mm}$. To remove correlated regional noise and leftover regional postseismic deformation from the 2008 Mw 8.8 Maule earthquake, we refer each site's relative position to the continuous station MAUL, located $\sim 30 \mathrm{~km}$ NW of the study area (Fig. 1). For each GPS station, we calculate the mean velocity between February 2019 and February 2020. Figure 2 shows uplift and radial motion outward from a point on the western shore of the lake basin. Before 2016, the uplift rate was slowly decreasing (Le Mével et al. 2016). Since then, however, the new GPS results show an increase in velocity that is still ongoing as of June 2020 (Fig. 2 and S1). The GPS station MAU2 is moving upward at $291 \pm 2 \mathrm{~mm} /$ year between 2019 and 2020, the fastest uplift rate measured since the installation of the GPS network in 2012.

\section{InSAR}

All available SAR images covering LdM from 2007 to 2020 (Fig. 1) acquired by ALOS-1 PALSAR (tracks 112 and 113), TerraSAR-X/TanDEM-X (tracks 28, 111, and 119), and SENTINEL-1 Copernicus (paths 18 and 83) are analyzed using ISCE (v2.0; Rosen et al. (2012). The resulting interferograms map the displacement along the line of sight (LOS) between target pixels on the ground and the radar sensor aboard the satellite. These maps are multilooked, unwrapped, and coregistered to a common SAR acquisition date (Table S1). Interferograms with average temporal coherence lower than 0.7 are excluded. The phase delay due to a stratified troposphere is modeled and removed using the atmospheric model ERA5 from ECMWF and the PyAPS software (Jolivet et al. 2011; Jolivet et al. 2014). A bi-linear (planar) phase ramp is estimated and removed. The resulting seven stacks are then inverted to calculate a time series of displacement using the weighted,
Fig. 2 GPS vertical displacement time series for the five continuously recording stations at LdM from 2012 to 2020, relative to site MAUL

(Lon,Lat:

$-70.82146^{\circ},-35.80959^{\circ}$,

Fig. 1). Inset: vertical and horizontal velocity vectors estimated from displacement time series between 2019 and 2020 (horizontal displacement time series shown in Fig. S1)

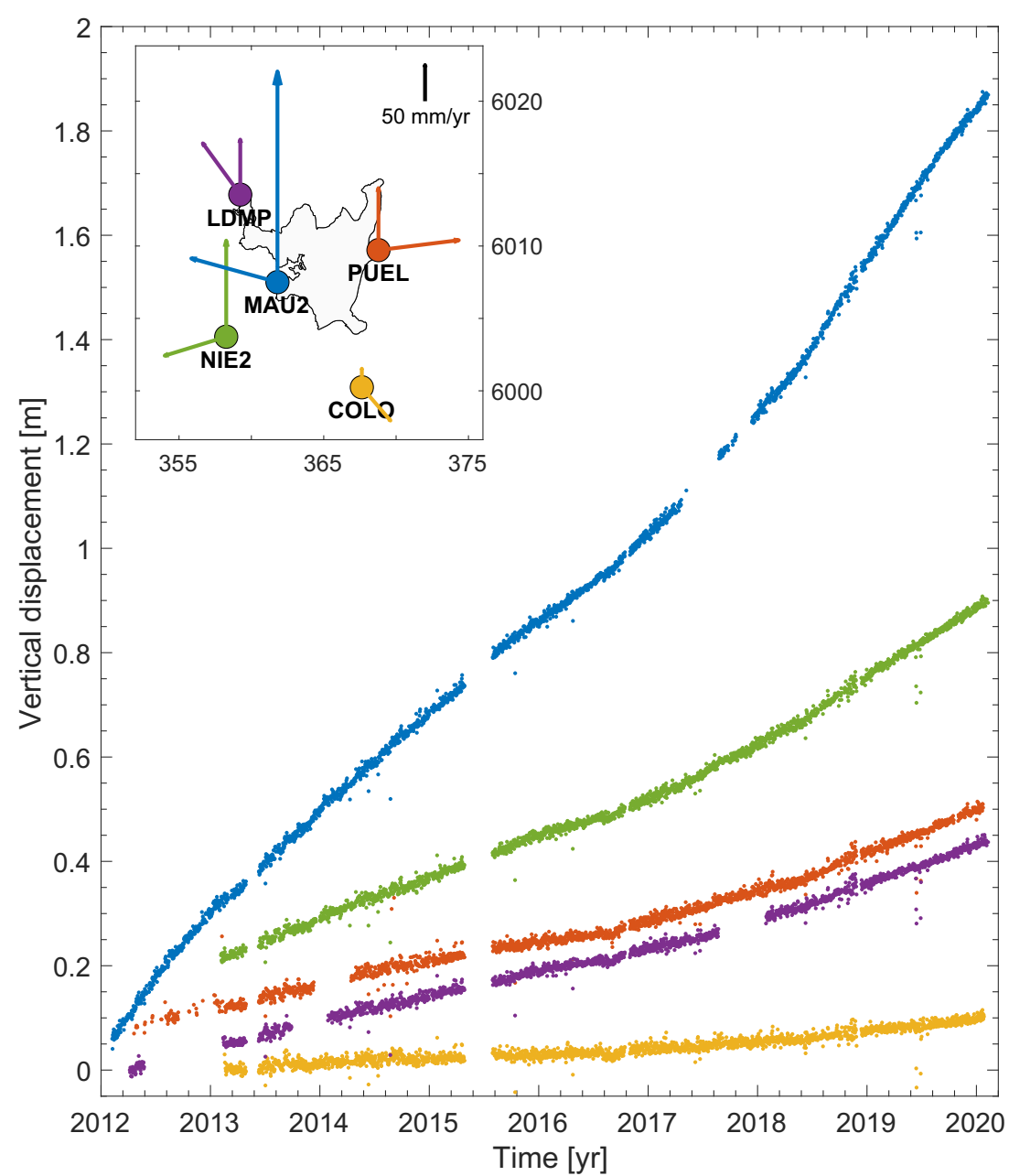


network-inversion approach of Yunjun et al. (2019) implemented in MintPy. We estimate the uncertainty for the displacement at each epoch as the sample standard deviation over a 3-by-3-pixel area around the pixel of interest. The maximum uncertainty for each track varies between 1.3 and $13.6 \mathrm{~mm}(0.21 \%$ and $1.98 \%$ of the displacement value, respectively) which is smaller than the symbols in Fig. 3. The InSAR time series agrees with the GPS (projected on each LOS vector for comparison) confirming the acceleration in late 2016 (Fig. 3).

\section{Deformation modeling}

\section{Methods}

In a first step, we fit the mean GPS velocities observed between 2019 and 2020 (Fig. 2). In our model, a constant change in pressure is applied at the boundary of a 3dimensional ellipsoidal cavity embedded in a heterogeneous viscoelastic crust with temperature-dependent viscosity (Del Negro et al. 2009; Gregg et al. 2012). The resulting ground displacement is calculated numerically using the finite element method in COMSOL Multiphysics (v.5.4). This type of numerical solution has been described in detail and compared with analytic solutions by Le Mével et al. (2016). We run 60,000 Monte Carlo simulations, randomly sampling the 9 model parameters: location (easting, northing, depth), dip, strike, principal semi-axes $(a, b, c)$ of the ellipsoid and the applied overpressure $\Delta P$ (Fig. 4). We calculate and minimize the misfit to the GPS data as a $\chi^{2}$ statistic: $\chi^{2}=\sum_{i=1}^{n}\left(\left(u_{o b s}-u_{\text {mod }}\right) / \sigma_{o b s}\right)_{i}^{2}$, where $n=15$ is the number of GPS measurements of displacement ( 3 components at 5 stations), $u_{o b s}$ is the annual displacement between 2019 and 2020 measured by GPS with uncertainty $\sigma_{o b s}$, and $u_{m o d}$ is the modeled annual displacement. A statistical F-test with 6 degrees of freedom (Bevington et al. 1993) yields the critical value of $\chi^{2}$ that delimits the $68 \%$ confidence intervals (Fig. S2). The geometry of the best-fitting model and the modeled annual displacement at each GPS site are shown in Fig. 4.

Second, we describe the temporal evolution of the surface displacement using a dynamic model of magma injection into the reservoir. As described in Le Mével et al. (2016) and sketched in Fig. 4c, we assume viscous magma flowing upward through a vertical conduit into a fluid-filled magma reservoir. We assume the magma to be an incompressible Newtonian fluid. A time-dependent overpressure $\Delta P_{i}(t)$ is applied at the conduit's inlet located at the base of the crust. The governing equations account for laminar flow in the fluid domain, stress in a linear viscoelastic (Maxwell) solid, and the two-way coupling at the interface between them. The numerical solution calculated using COMSOL is fully 3-dimensional and time-dependent. This model includes seven parameters: the starting time $t_{0}$ of the first magma injection, the time $t_{1}$ of the first inflection point, the maximum pressure $P_{1}$ reached at $t_{1}$, the starting time $t_{2}$ of the second increase in inlet pressure, the maximum inlet pressure $P_{3}$ reached at the end of the simulation, the conduit radius $a_{c}$, and the magma viscosity $\eta_{m}$ (Fig. 5).

To optimize the 7 model parameters, we consider the LOS displacement time series from ALOS T112 (Fig. S3) and the GPS time series of vertical displacement at MAU2, decimated to 42 data points (one measurement every 60 days) (Fig. 2). After running 6000 Monte Carlo trial simulations, we retain the set of values that minimizes the misfit to the data using the $\chi^{2}$ statistic.

\section{Magma reservoir geometry modeling results}

The model that best fits the 2019-2020 GPS velocity vectors finds an ellipsoidal source with principal axes $a=7.06 \mathrm{~km},(a \in[5.70,8.05] \mathrm{km}), b=1.90 \mathrm{~km},(b \in$ $[1.55,2.74] \mathrm{km})$, and $c=1.35 \mathrm{~km},(c \in[0.96,2.09] \mathrm{km})$, located at $X_{U T M}=363.58 \mathrm{~km},\left(X_{U T M} \in[363.22,364.30]\right.$ $\mathrm{km}), Y_{U T M}=6007.30 \mathrm{~km},\left(Y_{U T M} \in[6007.01,6007.90]\right.$ $\mathrm{km})$, at a depth $d=4.78 \mathrm{~km},(d \in[5.48,3.89] \mathrm{km})$, and overpressure $\Delta P=4.39 \mathrm{MPa},(\Delta P \in[2.66,5.48] \mathrm{MPa})$ (Figs. 4 and S2). The best-fit ellipsoid is centered offshore between the western peninsula and the rhyolite flow of Las Nieblas (star on Fig. 4). The source is oriented NE-SW (azimuth $\phi=\mathrm{N} 25^{\circ} \mathrm{E}, \phi \in[10,42]^{\circ} \mathrm{E}$ ), slightly dipping to the NW (plunge $\theta=-3^{\circ}, \theta \in[-21,10]^{\circ}$ ). This orientation resembles that of the Troncoso normal fault, one of the major structural features in the basin, and of the faults mapped under the lake (Garibaldi et al. 2020; Peterson et al. 2020). The location and spatial extent of the deformation pattern do not appear to have changed through time, as evidenced by the similarity of the new model geometry to the best-fitting dislocation model estimated previously by Feigl et al. (2014) and Le Mével et al. (2015). This ellipsoid explains the GPS velocities well (Fig. 4). The $\chi^{2}$ misfit decreases from $\sim 10^{5}$ to $10^{3}$ (Fig. S2). The residual velocities are less than $14 \mathrm{~mm} /$ year and $33 \mathrm{~mm} /$ year for the horizontal and vertical components, respectively, at all 5 GPS stations (i.e. $11 \%$ of the displacement rate). While most of the volcanic inflation signal is explained by the model of a pressurized ellipsoidal source, the residuals to the InSAR velocity maps (Fig. S4) reveal additional localized deformation, including subsidence on the rhyolite flow SW of the lake basin and possibly motion along the Troncoso fault. Modeling these additional deformation sources is beyond the scope of this paper. The geometry of our bestfitting model for the deformation source is in accordance 
Fig. 3 (Left column) LOS

velocity maps from stack of TerraSAR-X and SENTINEL interferograms (Table S1) spanning 2019 to 2020, and GPS site MAU2 (black triangle). (Right column) LOS displacement time series for each SAR track calculated for pixel at MAU2 (blue circles) and GPS observations projected onto each LOS (beige dots)
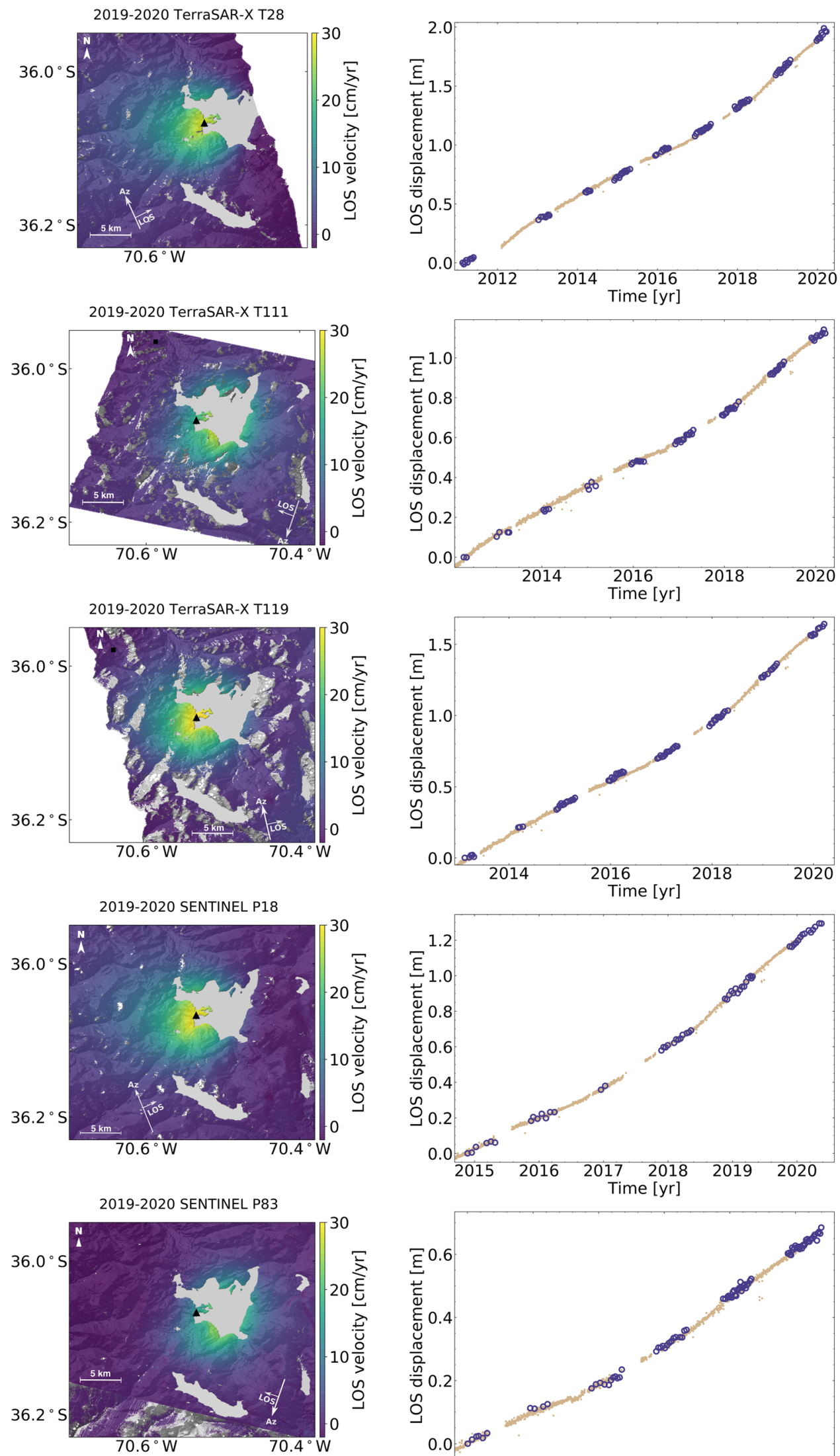


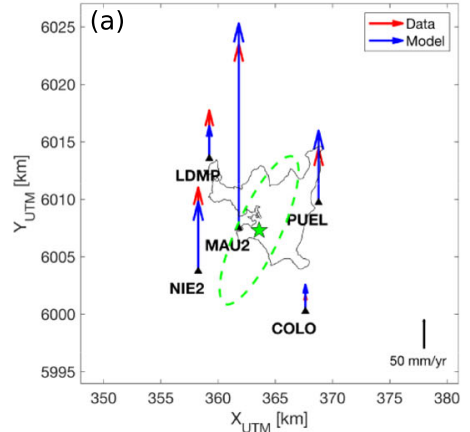

Fig. 4 Modeled (blue) and observed (red) vertical (a) and horizontal (b) GPS velocities estimated between 2019 and 2020 from time series shown in Figs. 2 and S1, with centroid (green star), surface projection of the 3D-ellipsoid (green dashed line), seismicity recorded at LdM from 2011 to 2020 (filled gray circles, size proportional to local magnitude $M_{L}\left(M_{L} \leqslant 3.3\right)$ ), location of $\mathrm{CO}_{2}$ gas anomaly (orange diamond),

with previous models, including: the Okada dislocation of Feigl et al. (2014), the ellipsoid of Novoa et al. (2019), as well as the 2-D axisymmetric ellipsoids of Le Mével et al. (2016) and Zhan et al. (2019).

\section{Dynamic modeling results}

We assume that the two inflection points identified on the uplift time series indicate two periods of magma injection and model them by an increase in pressure at the inlet of the conduit (Fig. 5, time intervals I and III). During time interval II, the inlet pressure is constant and the magma continues to flow to the reservoir but with decreasing flow rates, leading to decreasing surface uplift rates. The best-fitting model shows: an increase in conduit inlet pressure from $P_{0}=0$ to $P_{1}=48.8 \mathrm{MPa}\left(P_{1} \in[45.6,50.0]\right.$ $\mathrm{MPa})$ between $t_{0}=2005.31\left(t_{0} \in[2005.08,2006.13]\right)$ and $t_{1}=2010.75\left(t_{1} \in[2010.18,2010.97]\right)$, and a second increase from $P_{2}=P_{1}$ to $P_{3}=79.9 \mathrm{MPa}\left(P_{3} \in[77.3,84.7]\right.$ MPa) between $t_{2}=2016.73\left(t_{2} \in[2016.54,2017.03]\right)$ and $t_{3}=2020.11$, with magma viscosity $\eta_{m}=7.1 \times 10^{9}$ Pa s $\left(\eta_{m} \in\left[5.8 \times 10^{9}, 7.5 \times 10^{9}\right] \mathrm{Pa} s\right)$, and conduit radius $a_{c}=82 \mathrm{~m}\left(a_{c} \in[78,84] \mathrm{m}\right)$. The two episodes of magma injection are thus described with very similar rates of pressure increase, 9.0 and $9.2 \mathrm{MPa} /$ year, respectively. Integrating the magma flow rate rising through the conduit to the reservoir $Q(t)$ over time gives the cumulative magma injection volume $\Delta V(t)$ as a function of time (Fig. 5). In total, $369 \times 10^{6} \mathrm{~m}^{3}$ of magma was added to the ellipsoidal reservoir. The fit to the time series is good with residual displacements less than $52 \mathrm{~mm} \mathrm{(3 \% )}$ and $46 \mathrm{~mm} \mathrm{(5 \% )} \mathrm{for}$ the GPS and InSAR-derived displacements, respectively, at each of the 51 data points included in the inversion (Fig. 5). The $\chi^{2}$ misfit decreases from 0.024 to 0.009 (Fig. S5).

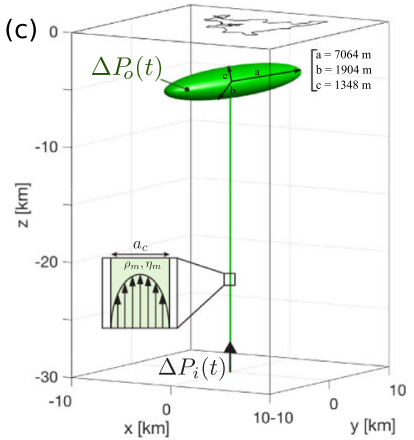

and the Troncoso fault (brown line); $\mathbf{c}$ zoomed view of the 3D model block used in the COMSOL FEM model (full width and length are 50 $\mathrm{km})$. Following the application of inlet pressure $\Delta P_{i}(t)$ at the base of the conduit, magma flows into and pressurizes an ellipsoidal reservoir $\left(\Delta P_{o}(t)\right)$ deforming the surrounding viscoelastic crustal domain

\section{Discussion}

The seismic monitoring network at LdM consists of 6 broadband seismometers installed between 2011 and 2013 (Cardona et al. 2018). The seismicity recorded between 2011 and 2020 occurs as repetitive swarms of volcanotectonic (VT) earthquakes of small magnitude $\left(M_{L} \leqslant 3.3\right)$, located mostly to the southwest of the volcanic field near the Troncoso fault at depths between 2 and $5 \mathrm{~km}$ (Cardona et al. 2018) (Fig. 4b). The southwest cluster of VT earthquakes coincides with the southwestern edge of the ellipsoidal reservoir modeled in this study. In the same area, recent measurements of diffuse $\mathrm{CO}_{2}$ degassing through soil have revealed an anomaly with a flux as high as $478.4 \mathrm{~g} / \mathrm{m}^{2} /$ day in March 2020 (Fig. 4b, OVDAS volcanic activity report of March 20, 2020). In addition, gravimetric changes measured between 2013 and 2016 align with the western edge of the modeled ellipsoid but indicates shallower mass injection at 1.5 to $2 \mathrm{~km}$ depth (Miller et al. 2017). The changes in deformation rates (inflection points) do not coincide with the occurrence of a particular earthquake swarm (Fig. 5). Nonetheless, the temporal evolution of the cumulative number of earthquakes seems to follow the longterm trend of the deformation rates. The cumulative number of earthquakes has decreased between 2014 and 2017 and conversely, have recently increased during interval III. We also note an increase in earthquake magnitude with more $M_{L}$ 2-3 earthquakes over the last two years. The most energetic seismic episode ever recorded at LdM happened in June 2020, with $\sim 2500$ seismic events recorded during three earthquake swarms on June 11, 13, and 16. All of these observations are consistent with a pressurizing magma reservoir at depth affecting the stress distribution in the surrounding crust and hence facilitating fluid motion and/or the reactivation of local faults, producing the observed 
Fig. 5 (Top) Modeled vertical displacement as a function of time (green line), InSAR data from ALOS T112 and T113 (black circles), and GPS (gray dots) observations at MAU2.

During time intervals I and III the measured uplift rates increase while they decrease during time interval II. For plotting purposes, each scalar LOS measurement from InSAR has been decomposed into the three components of displacement using the method outlined in Text S1; this calculation infers the vertical component of displacement from the observed LOS displacement by using the orientation from the modeled displacement vector.

Seismic events recorded at LdM (black bars, maximum daily number annotated on right axis) and cumulative number (blue line). (Middle) Inlet pressure applied at base of conduit (brown) and resulting fluid pressure in the reservoir (pink). (Bottom) Temporal changes in volume flow rate feeding the reservoir (purple) and cumulative volume of magma added to the reservoir (orange)
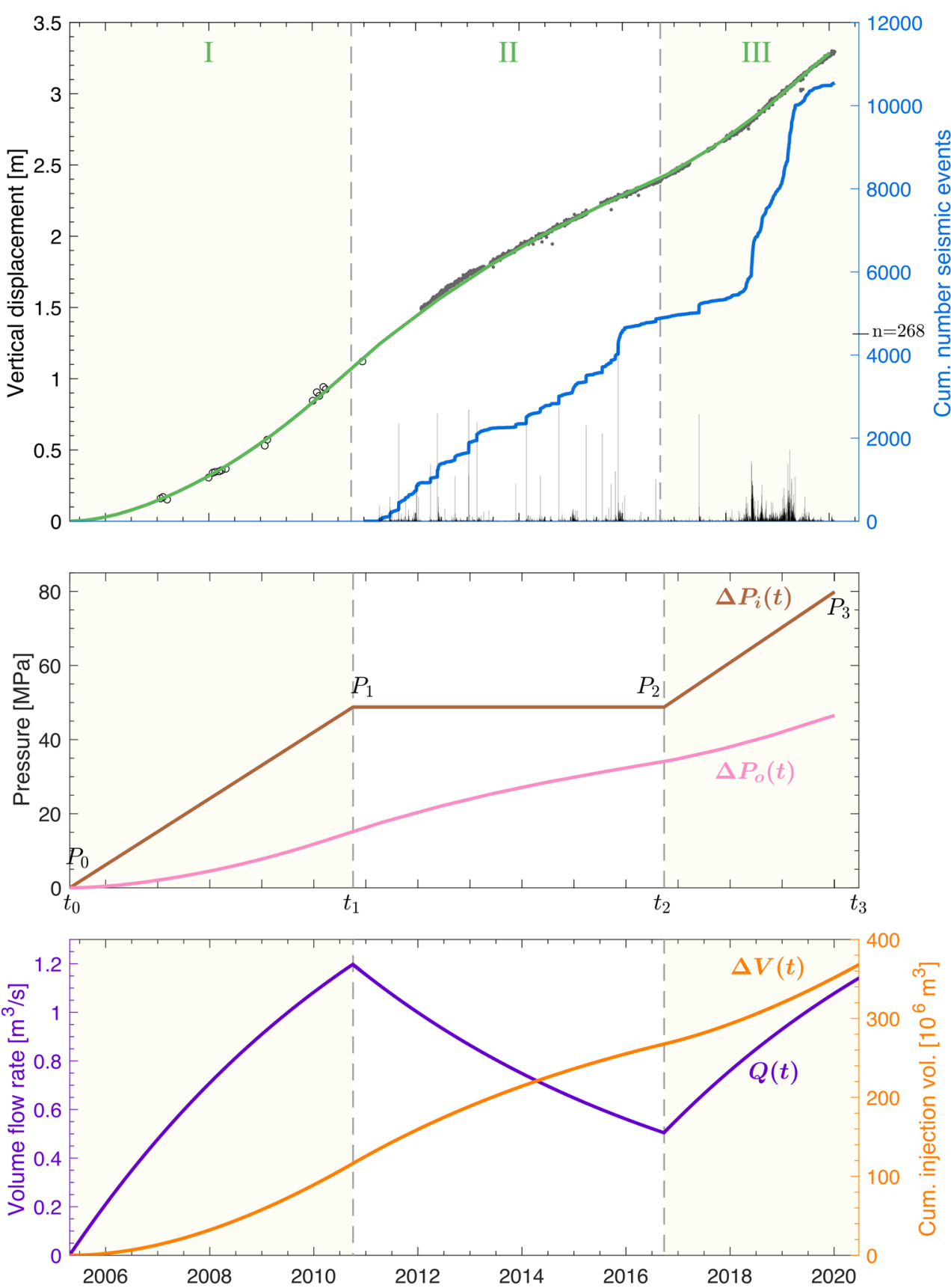

spatial and temporal patterns in seismicity and deformation (Garibaldi et al. 2020; Zhan et al. 2019).

The results from modeling the deformation field measured by GPS and InSAR indicate two distinct episodes of increased pressure feeding an ellipsoidal reservoir under the center of the lake basin. The temporal changes in uplift rates indicate that magma supply to the LdM magmatic system varies over short time scales of the order of several years. The total volume of magma added to the system between 2005 and 2020 is $0.37 \mathrm{~km}^{3}$, that is $0.45 \%$ of the total volume of the modeled reservoir $\left(81.7 \mathrm{~km}^{3}\right)$. The modeled rates of inlet pressure change are similar in each of the two intervals of accelerated deformation (2005-2010 and 2016-2020), indicating a similar underlying mechanism. This identified pattern might repeat regularly. The magma flow rate varies between 0 and $0.0377 \mathrm{~km}^{3} /$ year, yielding an average of $0.0243 \mathrm{~km}^{3} /$ year. The high magma recharge rates associated with volcanic unrest observed on the decadal timescale supports the hypothesis of episodic growth of magma bodies. Some $\sim 35$ episodes of non-eruptive intrusions of magma 
like the current one would be required to make up the 13 $\mathrm{km}^{3}$ estimated by Singer et al. (2018) to explain the $62-\mathrm{m}$ uplift of the paleoshoreline at LdM during the Holocene.

The high recharge rate at LdM is comparable to the volume change rate modeled during the ongoing unrest at Domuyo volcano (Lundgren et al. 2020), a silicic volcanic center $\sim 50 \mathrm{~km}$ to the SE of LdM. In their statistical study of caldera unrest, Sandri et al. (2017) show that the majority of pre-eruptive unrest lasts less than 18 months and display high rates of seismicity and degassing. The long duration of unrest at LdM ( $\sim 15$ years) and relatively low seismic activity is typical of non-eruptive caldera unrest episodes, as also observed at Long Valley, Campi Flegrei or Izu-Oshima (Sandri et al. 2017). Nevertheless, the stress models of Zhan et al. (2019) show that the trajectory of the overpressure building up in the reservoir controls the occurrence and timing of potential failure at LdM. Our results showing renewed acceleration at LdM therefore have important implications for the future evolution of unrest and the hazard assessment at this volcano.

\section{Conclusions}

In this paper, we have analyzed and modeled new GPS and InSAR data revealing a renewed acceleration in uplift at LdM starting in late 2016 and reaching more than 290 mm/year between February 2019 and February 2020. The 2019-2020 GPS velocities are modeled using a 7.1 by 1.9 by $1.3 \mathrm{~km}$ pressurized ellipsoid at a depth of $4.8 \mathrm{~km}$ in a viscoelastic crust. We then use a dynamic model of magma injection to describe the uplift time series from 2005 to 2020 and find that two episodes of magma injection have accumulated a total volume of $0.37 \mathrm{~km}^{3}$. Both intervals of accelerating uplift are explained with a similar rate of inlet pressure increase ( $\sim 9 \mathrm{MPa} /$ year $)$. If the new episode follows the previous pattern observed between 2005 and 2010, we could expect the uplift rates to keep increasing for two additional years. The rapid deformation, together with increasing seismicity and $\mathrm{CO}_{2}$ degassing, demonstrates the need for continued monitoring at the Laguna del Maule volcanic field.

Supplementary information The online version contains supplementary material available at https://doi.org/10.1007/s00445-021-01457-0.

Acknowledgements The authors thank the editors Drs. Joël Ruch and Andrew Harris, and two anonymous reviewers for providing helpful comments that helped to improve the manuscript. The authors also thank Brad Singer and Nathan Andersen for helpful discussions. We thank the following organizations for facilitating access to data: DLR (research project RES1236), JAXA, ESA, UNAVCO, WinSAR, and ASF. This research was partially supported by grants from the U.S. National Science Foundation (EAR1411779 - HLM \& KLF) and Jet Propulsion Laboratory (SRTD 1641138 to KLF). KLF gratefully acknowledges sabbatical support from a Merle Tuve Fellowship at
Carnegie, the Center for Academic Partnership at JPL, and the College of Letters \& Science at the University of Wisconsin-Madison. GNSS and seismic data can be requested to OVDAS (SERNAGEOMIN). The COMSOL MPH files are available upon request. InSAR time series products are available at https://zenodo.org/record/4662908.

Open Access This article is licensed under a Creative Commons Attribution 4.0 International License, which permits use, sharing, adaptation, distribution and reproduction in any medium or format, as long as you give appropriate credit to the original author(s) and the source, provide a link to the Creative Commons licence, and indicate if changes were made. The images or other third party material in this article are included in the article's Creative Commons licence, unless indicated otherwise in a credit line to the material. If material is not included in the article's Creative Commons licence and your intended use is not permitted by statutory regulation or exceeds the permitted use, you will need to obtain permission directly from the copyright holder. To view a copy of this licence, visit http://creativecommons. org/licenses/by/4.0/.

\section{References}

Andersen NL, Singer BS, Coble MA (2019) Repeated rhyolite eruption from heterogeneous hot zones embedded within a cool, shallow magma reservoir. J Geophys Res Solid Earth 124(3):2582-2600

Andersen NL, Singer BS, Costa F, Fournelle J, Herrin JS, Fabbro GN (2018) Petrochronologic perspective on rhyolite volcano unrest at Laguna del Maule, Chile. Earth Planet Sci Lett 493:57-70

Astort A, Walter TR, Ruiz F, Sagripanti L, Nacif A, Acosta G, Folguera A (2019) Unrest at Domuyo Volcano, Argentina, detected by geophysical and geodetic data and morphometric analysis. Remote Sens 11(18). https://www.mdpi.com/2072-4292/ $11 / 18 / 2175$

Bai T, Thurber C, Lanza F, Singer BS, Bennington N, Keranen K, Cardona C (2020) Teleseismic tomography of the Laguna del Maule volcanic field in Chile. J Geophys Res Solid Earth 125(8). https://agupubs.onlinelibrary.wiley.com/doi/abs/10.1029/ 2020JB019449

Bevington PR, Robinson DK, Blair JM, Mallinckrodt AJ, McKay S (1993) Data reduction and error analysis for the physical sciences. Comput Phys 7(4):415-416

Cardona C, Tassara A, Gil-Cruz F, Lara L, Morales S, Kohler P, Franco L (2018) Crustal seismicity associated to rpid surface uplift at Laguna del Maule Volcanic Complex, Southern Volcanic Zone of the Andes. J Volcanol Geotherm Res 353:83-94

Chang W-L, Smith RB, Farrell J, Puskas CM (2010) An extraordinary episode of Yellowstone caldera uplift, 2004-2010, from GPS and InSAR observations. Geophys Res Lett 37(23). https://agupubs. onlinelibrary.wiley.com/doi/pdf/10.1029/2010GL045451

Coco A, Gottsmann J, Whitaker F, Rust A, Currenti G, Jasim A, Bunney S (2016) Numerical models for ground deformation and gravity changes during volcanic unrest: simulating the hydrothermal system dynamics of a restless caldera. Solid Earth. http://hdl.handle.net/2122/10494

Cordell D, Unsworth MJ, Díaz D (2018) Imaging the Laguna del Maule Volcanic Field, central Chile using magnetotellurics: Evidence for crustal melt regions laterally-offset from surface vents and lava flows. Earth Planet Sci Lett 488:168-180

Del Negro C, Currenti G, Scandura D (2009) Temperature-dependent viscoelastic modeling of ground deformation: Application to Etna volcano during the 1993-1997 inflation period. Phys Earth Planet Inter 172(3-4):299-309 
Dzurisin D (2007) Volcano deformation: new geodetic monitoring techniques. Springer, Berlin

Feigl KL, Le Mével H, Tabrez Ali S, Córdova L, Andersen NL, DeMets C, Singer BS (2014) Rapid uplift in Laguna del Maule volcanic field of the Andean Southern Volcanic zone (Chile) 2007-2012. Geophys J Int 196(2):885-901

Fournier TJ, Pritchard ME, Riddick SN (2010) Duration, magnitude, and frequency of subaerial volcano deformation events: New results from Latin America using InSAR and a global synthesis. Geochem Geophys Geosyst 11(1). https://agupubs.onlinelibrary. wiley.com/doi/pdf/10.1029/2009GC002558

Galetto F, Bagnardi M, Acocella V, Hooper A (2019) Noneruptive unrest at the Caldera of Alcedo Volcano (Galápagos Islands) Revealed by InSAR data and geodetic modeling. J Geophys Res Solid Earth 124(4):3365-3381

Garibaldi N, Tikoff B, Peterson D, Davis JR, Keranen K (2020) Statistical separation of tectonic and inflation-driven components of deformation on silicic reservoirs, Laguna del Maule volcanic field, Chile. J Volcanol Geotherm Res 389:106744

Gottsmann J, Folch A, Rymer H (2006) Unrest at campi flegrei: A contribution to the magmatic versus hydrothermal debate from inverse and finite element modeling. J Geophys Res Solid Earth 111(B7). https://agupubs.onlinelibrary.wiley.com/doi/pdf/ 10.1029/2005JB003745

Gregg PM, de Silva SL, Grosfils EB, Parmigiani JP (2012) Catastrophic caldera-forming eruptions: Thermomechanics and implications for eruption triggering and maximum caldera dimensions on Earth. J Volcanol Geotherm Res 241-242:1-12

Jolivet R, Grandin R, Lasserre C, Doin M-P, Peltzer G (2011) Systematic InSAR tropospheric phase delay corrections from global meteorological reanalysis data. Geophys Res Lett 38(17). https://agupubs.onlinelibrary.wiley.com/doi/pdf/10.1029/ 2011GL048757

Jolivet R, Agram PS, Lin NY, Simons M, Doin M-P, Peltzer G, Li Z (2014) Improving InSAR geodesy using global atmospheric models. J Geophys Res Solid Earth 119(3):2324-2341

Klug JD, Singer BS, Kita NT, Spicuzza MJ (2020) Storage and evolution of Laguna del Maule rhyolites: Insight from volatile and trace element contents in melt inclusions. J Geophys Res Solid Earth 125(8). https://agupubs.onlinelibrary.wiley.com/doi/pdf/10. 1029/2020JB019475

Le Mével H, Feigl KL, Córdova L, DeMets C, Lundgren P (2015) Evolution of unrest at Laguna del Maule volcanic field (Chile) from InSAR and GPS measurements, 2003 to 2014. Geophys Res Lett 42(16):6590-6598

Le Mével H, Gregg PM, Feigl KL (2016) Magma injection into a long-lived reservoir to explain geodetically measured uplift: Application to the 2007-2014 unrest episode at Laguna del Maule volcanic field, Chile. J Geophys Res Solid Earth 121(8):60926108

Lundgren P, Girona T, Bato MG, Realmuto VJ, Samsonov S, Cardona C, Franco L, Gurrola E, Aivazis M (2020) The dynamics of large silicic systems from satellite remote sensing observations: the intriguing case of Domuyo volcano, Argentina. Scientific Reports 10(1): 11642

Miller CA, Le Mével H, Currenti G, Williams-Jones G, Tikoff B (2017) Microgravity changes at the Laguna del Maule volcanic field: Magma-induced stress changes facilitate mass addition. J Geophys Res Solid Earth 122(4):3179-3196

Miller CA, Williams-Jones G, Fournier D, Witter J (2017) 3d gravity inversion and thermodynamic modelling reveal properties of shallow silicic magma reservoir beneath Laguna del Maule, Chile. Earth Planet Sci Lett 459:14-27
Mogi K (1958) Relations between the eruptions of various volcanoes and the deformations of the ground surfaces around them. Bull. Earthq. Res. Inst., Univ. Tokyo 36:99-134

Montgomery-Brown EK, Wicks CW, Cervelli PF, Langbein JO, Svarc JL, Shelly DR, Hill DP, Lisowski M (2015) Renewed inflation of Long Valley Caldera, California (2011 to 2014). Geophys Res Lett 42(13):5250-5257

Novoa C, Remy D, Gerbault M, Baez JC, Tassara A, Cordova L, Cardona C, Granger M, Bonvalot S, Delgado F (2019) Viscoelastic relaxation: A mechanism to explain the decennial large surface displacements at the Laguna del Maule silicic volcanic complex. Earth Planet Sci Lett 521:46-59

Peltier A, Famin V, Bachélery P, Cayol V, Fukushima Y, Staudacher $\mathrm{T}$ (2008) Cyclic magma storages and transfers at Piton de La Fournaise volcano (La Réunion hotspot) inferred from deformation and geochemical data. Earth Planet Sci Lett 270(3):180-188

Peterson D, Garibaldi N, Keranen K, Tikoff B, Miller C, Lara LE, Tassara A, Thurber C, Lanza F (2020) Active normal faulting, diking, and doming above the rapidly inflating Laguna del Maule volcanic field, chile imaged with chirp, magnetic, and focal mechanism data. J Geophys Res Solid Earth 125(8):e2019JB019329

Rosen PA, Gurrola E, Sacco GF, Zebker H (2012) The InSAR scientific computing environment. In: EUSAR 2012; 9th European conference on synthetic aperture radar, pp 730-733

Sandri L, Acocella V, Newhall C (2017) Searching for patterns in caldera unrest. Geochem Geophys Geosyst 18(7):2748-2768

Sigmundsson F, Hreinsdóttir S, Hooper A, Arnadóttir T, Pedersen R, Roberts MJ, Óskarsson N, Auriac A, Decriem J, Einarsson P, et al. (2010) Intrusion triggering of the 2010 Eyjafjallajökull explosive eruption. Nature 468(7322):426-430

Singer BS, Le Mével H, Licciardi JM, Córdova L, Tikoff B, Garibaldi N, Andersen NL, Diefenbach AK, Feigl KL (2018) Geomorphic expression of rapid Holocene silicic magma reservoir growth beneath Laguna del Maule, Chile. Science Advances 4(6). https:// advances.sciencemag.org/content/4/6/eaat 1513

Troiano A, Di Giuseppe MG, Petrillo Z, Troise C, De Natale G (2011) Ground deformation at calderas driven by fluid injection: modelling unrest episodes at Campi Flegrei (Italy). Geophys J Int 187(2):833-847

Wespestad CE, Thurber CH, Andersen NL, Singer BS, Cardona C, Zeng X, Bennington NL, Keranen K, Peterson DE, Cordell D, Unsworth M, Miller C, Williams-Jones G (2019) Magma reservoir below Laguna del Maule volcanic field, Chile, imaged with surface-wave tomography. J Geophys Res Solid Earth 124(3):2858-2872

Yunjun Z, Fattahi H, Amelung F (2019) Small baseline InSAR time series analysis: Unwrapping error correction and noise reduction. Computers \& Geosciences 133:104331

Zhan Y, Gregg PM, Le Mével H, Miller CA, Cardona C (2019) Integrating reservoir dynamics, crustal stress, and geophysical observations of the Laguna del Maule Magmatic system by fem models and data assimilation. J Geophys Res Solid Earth 124(12):13547-13562

Zumberge JF, Heflin MB, Jefferson DC, Watkins MM, Webb FH (1997) Precise point positioning for the efficient and robust analysis of GPS data from large networks. J Geophys Res Solid Earth 102(B3):5005-5017

Publisher's note Springer Nature remains neutral with regard to jurisdictional claims in published maps and institutional affiliations. 